\title{
Integração metodológica na Ciência da Religião*
}

Michael Pye**

\section{Agrupamento metodológico}

Estas páginas apresentam um chamado para uma abordagem integrada no estudo acadêmico das religióes que faz justiça à sua especificidade, mas sem separá-la artificialmente de outras formas relacionadas de pesquisa. A reflexáo de uma disciplina sobre seus métodos é parte normal de um empreendimento acadêmico, e isso se aplica tanto à Ciência da Religião (Religionswissenchaft) ${ }^{1}$ como a qualquer outra pesquisa científica. Essa afirmação implica que a Ciência da Religião deve ser visto como uma "disciplina". "Religiôes" constituem um campo de estudo - sendo assim, a Ciência da(s) Religião (Religiōes)" é uma disciplina. O que é uma disciplina no sentido científico? É nada mais que uma abordagem sistematicamente ordenada para o estudo de um campo. O campo "religião(óes)", não menos que qualquer outro campo, requer uma abordagem sistematicamente ordenada para seu estudo. Essa abordagem como disciplina tem características particulares, de acordo com o que é necessário para um melhor estudo do campo. Consequentemente, a disciplina que estuda a religião(óes) não é necessariamente a mesma disciplina exigida em outros campos, embora pareça similar àquelas usadas no estudo de campos intimamente relacionados.

A visão do campo e o entendimento do mesmo pela disciplina interagem. Uma perspectiva metodológica estável corresponde a uma visão estável do campo. A desestabilização de uma implica a desestabilização da outra. No entanto, um avanço na metodologia pode levar à correção da visão do campo e, por outro lado, novas características recentemente percebidas ou emergentes no campo podem levar a

\footnotetext{
* Tradução do artigo "Methodological Integration in the Study of Religions" (2014) por Mariana Fernandes de Souza.

** Professor emérito na Universidade de Marburg, Alemanha, e Research Associate no Instituto de Estudo Compreensivo do Budismo Shin, Universidade Otani, Kyoto, Japão.

${ }^{1} \mathrm{O}$ termo alemão (como seu equivalente em várias línguas) tem a vantagem de incluir o elemento "ciência" nele, mas a desvantagem de referir-se à religião no singular. Deve-se ter cautela e evitar termos que coloquem a ciência no plural, Religionswissenchaften, já que eles sugerem que de um lado a "religião" é uma entidade idealizada, evitando, do outro, a tarefa árdua de ser claro sobre qual a ciência apropriada para sua investigação.
} 
questionamentos na compreensão atual do método. A abertura à revisão de perspectivas é desejável; todavia, o pesquisador pode almejar certa estabilidade na compreensão de ambos, campo e disciplina, já que de outra forma a interação crítica entre investigadores individuais, típica de uma "ciência", não funciona. Espera-se que conferências sobre metodologia na Ciência das Religião, notadamente as acontecidas em $\mathrm{Turku}^{2}$, contribuam para o processo de estabilização. Dessa forma, a disciplina pode ser aprendida, praticada, ensinada, corrigida e desenvolvida.

O entendimento de que há, e que de fato deve haver, tal processo de desenvolvimento metodológico e reflexão, não implica que a Ciência da Religião tenha um método especial, único a ele. Ao mesmo tempo, a disciplina do Ciência da Religião exige um agrupamento de métodos. Embora os métodos à nossa disposição sejam conhecidos no contexto de outras disciplinas, eles são reunidos de uma maneira particular para facilitar o estudo preciso do campo em questáo, especificamente as religiôes. A disciplina resultante não é exatamente a mesma que as disciplinas necessárias para o estudo de outros campos, ou campos definidos de maneira diferente.

É desejável esclarecer, neste ponto da discussão, a natureza da especificidade que a disciplina pede e as razóes pelas quais ela deveria ser assim. Ela surge, primeiramente, da simples razáo de que parece não haver outra disciplina única que poderia alegar ser plausivelmente, e de forma precisa, a disciplina exigida para a Ciência da Religião. Por exemplo, a História não se encaixa nas demandas porque normalmente não inclui as sutilezas metodológicas para fazer o trabalho de campo com pessoas vivas. Nem a Sociologia, porque em geral, e de maneira correta para seus termos, subordina o estudo de ideias e comportamentos religiosos a questóes mais amplas sobre a natureza e o funcionamento da sociedade. Tais questóes são obviamente valiosas, mas há outras questôes de interesse no que diz respeito à religião, como por exemplo sua estrutura interna e dinâmicas, que não são necessariamente sociológicas em sua natureza. Por razóes análogas, Antropologia, História da Arte, Arqueologia, Ciências Políticas e assim por diante não equivalem à disciplina exigida, de modo geral, somente para a Ciência da Religiáo. Infelizmente, as palavras "autonomia" e "autônomo" têm sido, algumas vezes, mal interpretadas ou usadas equivocadamente. Isso porque elas são frequentemente associadas a uma visão "essencialista” ou sui generis da religião como um fenômeno unitário, ou seja, com a ideia de que por trás

\footnotetext{
${ }^{2}$ Refiro-me às conferências da IAHR sobre metodologia em 1973 (veja Honko, 1979) e em 1997. No todo, eu acredito que essas conferências tenderam a de fato estabilizar a metodologia, embora algumas contribuiçóes em cada caso possam proporcionar ilustraçóes para algumas das dificuldades discutidas na próxima seção deste trabalho.
} 
das várias religióes há uma essência unificadora, que apenas especialistas em religião podem entender. $\mathrm{O}$ que faz seus estudos diferentes de qualquer outro estudo. Essa posição não é, de forma alguma, adotada aqui. E nem deverá ser discutida a essa altura, já que tal visão da religião não é relevante ao argumento que está sendo desenvolvido ${ }^{3}$. Apontar o fato de que nenhuma outra disciplina atualmente praticada nas Ciências Humanas ou Sociais tem relação específica ou adequada com o campo "religiōes" é uma questão diferente.

De uma forma ou outra, elas falham em explorar devidamente ou elucidar o objeto. Algumas fazem pouco, outras fazem demais. Isso não significa que a Ciência da Religião exija um método especial, que seja único. Significa que a seleção correta dos métodos disponíveis pode ser feita, e que eles devem ser agrupados de uma maneira apropriada ao objeto.

Enquanto é necessário perceber que um agrupamento específico de métodos é um requisito para manter e desenvolver a disciplina da Ciência da Religião, não é necessariamente importante alcançar um consenso sobre como esse agrupamento deve ser. Consequentemente, não há intenção de apresentar uma declaração dogmática sobre isso aqui. Todavia, depois de abrir caminho com algumas notas sobre as dificuldades atuais e suas razóes, a seguinte apresentação procurará mostrar como esse agrupamento de métodos poderia ser. Ela é formulada a partir do que, para alguns, podem ser termos decepcionantemente descomplicados. No entanto, isso é intencional e visto aqui como uma vantagem. Simplicidade é um ponto forte, e não uma fraqueza. Aqueles que estão engajados com a Ciência da Religião na prática acharão relativamente fácil chegar num acordo geral com essas linhas. E é de fato importante, enquanto continuamos com a discussão metodológica dentro da disciplina, que haja uma tradição vastamente reconhecível do estudo que possa ser identificado como a "Ciência da Religiáo" (ou qualquer outra formulação de preferência). De fato, essa tradição reconhecível do estudo já existe, mesmo que precise de maior cristalização.

\section{Razóes para algumas dificuldades atuais}

Infelizmente, apesar de toda atenção às questóes metodológicas no estudo da religião, ainda há incerteza, indefinição e até irresponsabilidade em certas áreas. Por

\footnotetext{
${ }^{3}$ Pode ser dito, para evitar qualquer mal-entendido, que a intenção no uso da frase "O estudo da religião é uma disciplina autônoma” (Pye, 1982) é consistente com a abordagem feita aqui. Infelizmente, a palavra "autônomo" pode ter muitas associaçóes equivocadas e deveria ser, talvez, evitada.
} 
que a identidade metodológica do estudo da religião é tão amplamente malentendida? Há várias razóes para isso.

Primeiramente, é deplorável o fato de que distinçóes básicas, que deveriam ser facilmente compreendidas, continuem a ser tratadas sem cautela ou descartadas como insignificantes. Um exemplo clássico disso é a diferença entre estudar declarações religiosas e fazer declaraçóes religiosas. É surpreendente, mas verdadeiro que, até hoje, depois de décadas de esclarecimentos metodológicos, ainda seja necessário fazer essa distinção clara. Repetidas vezes, teólogos parecem confiantes em fazer declarações que julgam pertencer ao Religionswissenschaft, quando na verdade estão fazendo uma análise religiosa de alguma situação cultural. Não é de se estranhar que outros membros do público, ou até mesmo da academia, não se deem ao trabalho de fazer essa distinção. No entanto, conforme muitos reais especialistas na Ciência da Religião concordariam hoje, é bastante significativo para o estudo da religião que ele não seja identificado com a produção de declarações religiosas. Essa seria uma questão para teólogos, budistas apologéticos, neoxamanistas e muitos outros.

Em segundo lugar, há certa compartimentalização intelectualmente obstinada promovida pelo uso de frases convencionais como "Religião Comparada", "Fenomenologia da Religião", "Antropologia da Religião", "Psicologia da Religião" e assim por diante. Embora normalmente tenham reconhecidamente uma certa história, que é repetida de tempos em tempos, não é tão comum ver esses termos avaliados criticamente, tendo em vista sua correlação, integração ou abandono, conforme seja necessário. Sáo mais comumente apenas listadas como opçóes que as pessoas podem seguir como quiserem. No entanto, se o campo é visto como coerente, um maior nível de coordenação metodológica, ou até integração, é intelectualmente desejável e deve, dessa forma, ser buscado. Por exemplo, o "estudo comparado das religiōes" náo pode existir sozinho. O mesmo serve para a "Etnologia da Religião", apesar da valiosíssima contribuição daqueles que trabalham na interface entre Etnologia e a Ciência da Religião ${ }^{4}$.

Em terceiro lugar, pessoas que acabaram de chegar ao tema normalmente trazem perspectivas metodológicas que foram fortemente formadas em outros contextos disciplinares. Isso normalmente é enriquecedor, mas também pode perpetuar suposiçóes equivocadas e mal-entendidos sobre a Ciência da Religião. Deste modo, pode acontecer de uma pessoa que foi treinada como um antropólogo ou etnólogo, e que se especializa em religião, simplesmente não se dar ao trabalho de adquirir orientação metodológica na disciplina da Ciência da Religião.

\footnotetext{
${ }^{4}$ Frases no padrão "etnologia de x" e equivalentes em outras línguas, como “ $x$-ethnologie”, são facilmente forjadas mas normalmente muito imprecisas em seus significados.
} 
Humanamente falando, isso pode ser aceitável, dependendo do caso e da situação, mas se torna irresponsável quando é dito aos alunos mais jovens, novos no assunto, que a Ciência da Religiáo não possui um método em particular. Nesses casos, parece que os pesquisadores em questão possuem uma necessidade profissional de continuar a ser identificados, sobretudo, como o que eram antes. Antropólogos, por exemplo, uma vez que começam sua dupla iniciação pelo trabalho em campo e fazem sua primeira publicação, agem algumas vezes como escoteiros que possuem o lema "uma vez escoteiro, sempre escoteiro". O resultado é o fracasso em alcançar "identificação com a disciplina".

Uma quarta razão para certa confusão é o desenvolvimento de divergências metodológicas sérias como resultado de um interesse por novas linhas de pensamento, que parecem ter suas próprias alegaçóes metodológicas. Algumas vezes, novos insights em uma direção em particular parecem encobrir completamente a discussáo metodológica, enquanto os ganhos iniciais são desprezados ou esquecidos. Por exemplo, pelo fato de que é interessante considerar a religião como um padrão das funções do cérebro, somos tentados a enxergar a ciência cognitiva como $o$ método apropriado para estudar religióes. Se não formos cuidadosos, a necessidade de um trabalho de campo, de estudos textuais e de comparação disciplinada pode ser esquecida. Colocando de uma maneira mais generalizada, não é infrequente que figuras interessantes como Claude Lévy-Strauss ou Michael Foucault façam esse papel, criando um efeito manada que desconsidera alguns dos requisitos metodológicos cotidianos da Ciência da Religiáo. O impacto de várias correntes intelectuais deve certamente ser encarado com entusiasmo por especialistas em religião, como no caso de outras disciplinas, mas ao mesmo tempo é necessário trabalhar com cautela onde as possibilidades de integração repousam. Caso contrário, métodos testados e válidos serão simplesmente deixados de lado ou esquecidos em favor de uma série de modismos.

Em quinto lugar, recentemente tem ocorrido um crescente reconhecimento de que a História das Religióes não é, e de fato nunca realmente foi, a mesma História de uma maneira mais geral. $\mathrm{O}$ esboço dentro do campo da História implicado pela junção do termo "das religiôes" implica um horizonte teórico insipiente. Tem sido, no entanto, assegurado com certa frequência que a "História das religióes traz em si o estudo sistemático, comparado e tipológico das religiões". No entanto, isso não é suficiente. Fazer simplesmente essa conexão não oferece a integração metodológica necessária. Além do mais, essa postura tira a atenção da possibilidade de um

\footnotetext{
${ }^{5}$ Embora pareça soar, de alguma forma, ameaçadora, essa frase (Pye, 1991) refere-se a um processo normal e apropriado em qualquer disciplina que é enriquecida por reforços de lugares variados.
} 
valiosíssimo campo de pesquisa entre numerosas religióes abertas a estudo direto atualmente. Ela é adotada tipicamente por aqueles que preferem rejeitar as contribuições metodológicas de muitas ciências sociais em favor de um método "históricofilológico". A abordagem também obscurece o ponto importante de que "a comparação" pode ser feita no que diz respeito às características internas da religião (levando a tipologias típicas da escola fenomenológica), e também no que diz respeito a explicaçóes funcionais sobre um espectro muito mais amplo da pesquisa sociológica e psicológica. Não se pode simplesmente dizer que é a parte "comparativa” da pesquisa que de alguma forma faz a Ciência da Religião sistemática e, assim, científico, ou que essa característica em si faz dessa disciplina algo distinto.

Em sexto lugar, a discussão seguiu adiante nos últimos anos. Tornou-se largamente aceito, contrariando a última tendência mencionada, que a História das Religióes só pode ter sentido total para a Ciência da Religião se o último também for compreendido como algo localizado dentro do cenário maior das ciências sociais e/ou culturais. Todavia, esses dois grandes segmentos, histórico-filológico (normalmente com ênfase no estudo de textos) e científico-social, são algumas vezes contrastantes e até nocivos um ao outro. O debate recente sobre o nome da International Association for the History of Religions (IAHR), conduzido durante os anos de 1990-95, reflete essas tensóes, embora tenha apresentado alguns aspectos pragmáticos. Em geral, pode ser dito que, por causa das variadas formaçóes acadêmicas pelo mundo, representantes de diversas tendências nessa discussão nem sempre têm facilidade em se entender. Esse foi o caso inclusive quando algumas posiçóes importantes foram compartilhadas, como na contribuição de Ugo Bianchi e Donald Wiebe ${ }^{6}$.

Por todas essas razóes, estudantes e jovens pesquisadores frequentemente sentem incerteza e falta de direção. Contudo, é discutido aqui que um nível de concordância considerável pode ser percebido na experiência de especialistas sobre como conduzir a Ciência da Religião. Vamos agora, desse modo, a consideraçóes estratégicas para o desenvolvimento de uma metodologia integrada para a Ciência da Religião das religiōes.

\section{Consideraçóes estratégicas}

Já não é mais suficiente simplesmente dispor em uma miscelânea, como frequentemente tem sido feito, as aparentemente variadas tarefas da História, da

\footnotetext{
${ }^{6}$ Suas declaraçôes e outras contribuiçôes relacionadas são preservadas nos anais informais da IAHR entre 1990 e 1995, quando a discussão aconteceu.
} 
sistematização, da Fenomenologia, da Hermenêutica, da Sociologia, da Picologia e assim por diante. É preciso fazer o esforço necessário para correlacionar e integrar claramente essas características de metodologias acadêmicas (em algumas línguas “científicas”), que são particularmente necessárias na Ciência da Religião. Isso trará discussóes muito mais frutíferas e verdadeiramente interdisciplinares com especialistas em outras disciplinas. Quais são, então, os pontos chave para um Ciência da Religiáo metodologicamente integrado? Sem a intenção de ser definitivo, esse artigo irá agora seguir dando uma resposta amplamente concebida para essa questão. Três pontos focais na articulação de uma metodologia integrada para o estudo disciplinado das religióes serão brevemente mencionados e depois tratados com mais detalhes a seguir.

Primeiro, há a relação entre o objeto e o método. Certa orientação metodológica advém da mais simples morfologia do objeto disponível. Isso resulta mais num esboço do campo a ser estudado do que em uma definiçáo assertiva do objeto de estudo. Os quatro aspectos para os quais chamo atenção são: o comportamental, o conceitual, o subjetivo e o social. Essa enumeração é reduzida aqui da forma mais simples possível sem óbvia omissão, e mais detalhes e argumentaçóes podem ser encontrados em outro lugar (Pye, 1972; Pye, 1994). Também será notado que esses quatro aspectos elementares são enumerados em tal nível de abstração que eles também podem ser discernidos em outros objetos, por exemplo, esporte ou política. No entanto, assim que o padrão é preenchido com um exemplo (ou "um caso") de religião, certas exigências metodológicas emergem claramente, o que pode não ser aplicável da mesma maneira em todos os outros campos de pesquisa. Isso será explicado abaixo.

O segundo foco é a relação entre fontes e métodos. As fontes não são a mesma coisa que o objeto. O objeto é um combinado complexo de informaçóes socioculturais para o qual as fontes fornecem evidências. A questão metodológica aqui é, dessa forma, como as fontes em questão poderiam ser estudadas. Deste modo, o foco nas fontes nos leva a orientações metodológicas secundárias, que vêm da natureza tríplice das fontes primárias disponíveis para o estudo, a saber: fontes escritas, orais ou materiais. Não há um método único aqui que seja particularmente característico ao Ciência da Religião. No entanto, há um agrupamento de métodos característicos que vem de uma reunião particular de fontes relevantes. Como será visto, um dos requisitos mais importantes nesse sentido é alcançar uma correlação coerente entre 
método "histórico-filológico" e os métodos típicos do trabalho em campo em situações "vivas” e "orais".

O terceiro ponto focal repousa nos requisitos da formação da teoria. É necessário fazer a distinção entre "teoria" e "método" porque um interesse em novas teorias é frequentemente confundido com avanço metodológico. Por exemplo, a teoria nas relaçóes de gênero na religião, ou um interesse em semiótica ou cibernética, não necessariamente implica o avanço ou mudança na metodologia tal como ela é. Reconhecidamente, novas posiçóes teóricas podem levar a algum ajuste metodológico. No entanto, há dois aspectos principais do método que contribuem em um nível particular para o desenvolvimento de categorias e teorias no estudo de religióes, a saber: comparação e contextualização. Como não são tão excitantes quanto novas abordagens teóricas vindas de outros lugares, elas são algumas vezes negligenciadas e desprezadas. Por outro lado, elas sáo eventualmente enfatizadas demais. O principal problema aqui é correlacioná-las apropriadamente com os requisitos que emergem de um objeto e das fontes disponíveis.

\section{Objeto e método}

Esses três pontos focais serão agora explicados com um pouco mais de detalhe. Como indicado acima, a enumeração dos aspectos comportamentais, sociais e subjetivos da religião são vistos aqui como sendo a mais breve indicação do objeto, o que mantém sua visão holística. Ou seja, essa enumeração nos permite pensar no objeto ao mesmo tempo de forma mais detalhada e geral. Pode ser que a mesma enumeração seja aplicada a outros objetos, mas a figura ganha cor no Ciência da Religião quando religióes ou uma religião em particular é vista dessa maneira. Qualquer delimitação futura nos leva a questóes mais complexas sobre morfologia e tipologia, e sobre quais diferenças de perspectivas podem surgir. No entanto, as discordâncias seriam teóricas e não metodológicas. No nível da atual reflexão metodológica, não importa se as perspectivas diferem sobre como quais teorias morfológicas deveriam ser desenvolvidas com mais detalhes, por exemplo, listando mais "dimensóes", assim como foi feito por Ninian Smart (Smart, 1996). Dessa forma, deveria ser notado que, em relação a esse ponto, estou preocupado apenas com os princípios metodológicos elementares que surgem da delimitação mais simples possível do objeto.

O primeiro requisito é que, assim que possível, ou melhor, assim que as fontes e os locais de pesquisa permitam, todos esses quatro aspectos elementares deveriam ser 
considerados em sua relação integral, um com o outro. Sob uma perspectiva mais negativa, por exemplo, ideias religiosas náo deveriam ser estudadas como se não tivessem qualquer relação com comportamentos religiosos. Se isso for feito, o pesquisador vai provavelmente terminar por simplesmente contribuir para próximos desenvolvimentos das tradiçóes religiosas em questão (assim como muitos que procuram o Ciência da Religiáo fazem de fato). Da mesma forma, os aspectos subjetivos da religião não podem ser completamente separados de seus acompanhamentos conceituais, um ponto que parece ainda ter a necessidade de ser debatido amplamente em conexáo com o misticismo ${ }^{7}$. Ou, novamente, que as formas sociais de religião não deveriam ser estudadas como se não importasse o que as pessoas envolvidas pensam, sentem ou fazem. Isso para dizer que os aspectos conceituais, subjetivos e comportamentais deveriam ser levados em conta ao mesmo tempo. Para propósitos práticos, um estudo parcial pode ser feito concentrando-se em um aspecto só, mas ao menos deveria ser reconhecido que outros aspectos são relevantes de forma latente. Em outras palavras, a religião deveria ser estudada detalhadamente e generalizadamente.

O segundo requerimento metodológico que vem do mesmo nível de análise é que um objeto com múltiplos aspectos deveria ser estudado, em primeira instância, em termos de seu significado integral para os crentes e participantes em questão. Em outras palavras, ele deveria ser estudado sem fazer referência à possível hipótese do pesquisador. Se não houver essa tentativa, a caracterização provavelmente será significativamente equivocada. Naturalmente, é perfeitamente legítimo e, de fato desejável, mais tarde, chegar a teorias explanatórias e, de fato, mais a seguir, a questionamentos de verdade e valor que vão além da tarefa do estudo de religióes (Religionswissenschaft). Mas, num primeiro momento, o Ciência da Religião deveria ser reconhecedor. Em outras palavras, o significado integral do objeto para os crentes ou participantes em questão deveria ser reconhecido em seu próprio direito. É isso que precisa ser elucidado e caracterizado em primeira instância. De outra forma, erros serão certamente cometidos, o que pode viciar qualquer outra forma de questionamento ou debate. A palavra "reconhecedor" foi recentemente forjada por conta de outras terminologias previamente usadas, como será ilustrado no próximo parágrafo.

Essa característica do método necessário inclui: a) elucidação e b) caracterização; dois passos sobre os quais uma discussão hermenêutica mais ampla é relevante.

7 Veja Mysticism and Religious Traditions (Katz, 1983), um trabalho de vários autores em que todos os colaboradores tomam essa perspectiva. 
O segundo requisito metodológico é, na verdade, um senso comum no Ciência da Religião desde o surgimento da tradição fenomenológica (no Ciência da Religião), e seria o fato do pesquisador colocar suas crenças pessoais "em suspensão". Infelizmente, o ponto tem sido frequentemente obscurecido porque se achou necessário rejeitar outras ênfases encontradas no trabalho daqueles que supostamente o adotaram. Foi mostrado muitas vezes, em particular, que principais representantes da escola fenomenológica náo procederam de fato fenomenologicamente nesse sentido, ou ao menos não de forma consistente. Em vez disso, eles colocaram seus materiais em categorias mais ou menos teológicas derivadas do ou particulares ao Cristianismo. G van der Leeuw e Friedrich Heiler são bons exemplos disso ${ }^{8}$. Apesar desse déficit, é muito importante que especialistas no Ciência da Religião continuem na tentativa de estudar as religióes como sistemas que possuem significados para seus crentes ou participantes. Anteriormente tentei preservar pelo menos o advérbio "fenomenologicamente" para indicar esse importante requisito metodológico. Tendo em vista a densa floresta de potenciais mal-entendidos, no entanto, eu agora decidi abandoná-lo de vez. Essa é a razão para a introdução da palavra "reconhecedor". Anteriormente, como outros, eu normalmente enfatizava a importância da “autocompreensão" dos crentes, e acredito que Jacques Waardenburg referiu-se a um ponto similar referindo-se às suas "intencionalidades" (Waardenburg 1986; $241 \mathrm{ff}$ ). No entanto, ambos os termos focam-se de forma um pouco pesada no aspecto conceitual da religião. O termo "reconhecedor" significa que o pesquisador dá total reconhecimento à complexa experiência coberta pelos quatro principais aspectos da religião para aqueles que estão envolvidos com ela.

Esse argumento inclui a ideia de que "especialistas no Ciência da Religião deveriam continuar tentando estudá-las como sistemas que possuem significado para seus crentes ou participantes", repetindo a frase já usada. A palavra "tentando" é colocada deliberadamente aqui porque é comumente sabido hoje que a total objetividade, ou não subjetividade, simplesmente não pode ser alcançada. Este não é o lugar para uma discussão geral sobre a viabilidade de uma ciência "livre de valores”. No entanto, eu rejeito firmemente a visão simplista de que, porque é difícil estudar sistemas religiosos em seus próprios termos, isso não deveria ser tentado. Aceitar tal visão afastaria a ciência em detrimento da mera arbitrariedade, e

\footnotetext{
${ }^{8}$ Não é necessário entrar em detalhes, mas deve ser chamada a atenção para artigos recentes de van der Leeuw (por Jacques Waardenburg) e de Heiler (por mim) no Klassiker de Religionswissenschaft, de Axel Michaels.
} 
simplesmente permitiria que velhos preconceitos fossem substituídos por novos. Embora a discussão epistemológica se torne mais sofisticada, ainda há diferença entre alcançar uma boa elucidação e caracterização da religião de um grupo específico de pessoas, ou entendê-lo de forma completamente equivocada porque a crença e valores do pesquisador estão continuamente no caminho.

$\mathrm{O}$ terceiro requisito metodológico vindo do objeto é que, mesmo que se proceda de forma reconhecedora por um lado, deveria ser dada a devida atençáo para a potencial emersão de questôes ou insights que entram em tensão, ou atravessam, a autocompreensão dos crentes ou participantes. Essa tensão aumenta com a movimentação da elucidação, passando pela caracterização até a explicação. Como resultado, a tensão surge por conta das seguintes três razóes, que podem formar uma característica particular da metodologia apropriada para o estudo da religiáo como um empreendimento complexo, mas integrado:

a) Dentro de qualquer exemplo estudado, uma estrutura pode aparecer, mas não ser aparente, ou ser parcialmente aparente, para os crentes ou participantes em questão. A percepçáo dessa estrutura pelo pesquisador pode, dessa forma, ser mais "correta" do que a do crente ou do participante (contando que eles se interessem pela matéria de alguma forma). Logo, nesse ponto, o primeiro grau de tensão emerge contra a ideia (que pode ser designada como "fenomenológica") de que os crentes estão "completamente certos" (Kristensen 1960:14).

b) A estrutura de qualquer religião pode ser representada mais visivelmente como um resultado de estudos comparativos, ou seja, o ainda contínuo, reconhecedor estudo de outros casos. Embora qualquer estudo em si continue a ser reconhecedor, a perspectiva teórica resultante do conhecimento comparativo pode não ser visível aos crentes e participantes, e caso se torne visível pode não ser aceitável. Esse é o segundo nível de tensão.

c) Finalmente, as intersecçóes de qualquer um dos quatro aspectos acima com contextos socioculturais ou históricos relacionados provavelmente farão emergir reflexóes correlacionadas que requerem, e sugerem, explicação no sentido mais forte da palavra. Essa é a tarefa normal das disciplinas mais abrangentes como a Sociologia ou a Psicologia, que possuem uma orientação explicativa mais forte. No entanto, isso também se aplica em outros estudos contextuais como a História intelectual, na medida em que ela inclui a História de ideias religiosas como parte de um todo muito mais abrangente, ou estudos comportamentais contextuais de diferentes tipos, tais como a pesquisa das funçóes do cérebro. 


\section{Fontes e métodos}

A enumeração dos quatro aspectos básicos da religião nos permitiu e nos exigiu dar os primeiros passos na definiçáo da metodologia necessária para seu estudo. Como dito anteriormente, a delimitaçáo do objeto em detalhe leva a questôes de morfologia e tipologia, e apenas secundariamente a questóes metodológicas. $\mathrm{O}$ próximo grande passo na identificação da correta metodologia repousa em outro lugar, a saber: em uma perspectiva geral das fontes. Novamente, dá-se preferência à perspectiva mais simples possível, que faz justiça ao todo. As fontes para o Ciência da Religião se encaixam em três principais grupos: as fontes escritas, as fontes orais e as fontes materiais. As fontes materiais aqui incluem artefatos, construçóes, símbolos não verbais, posições e movimentos corporais etc. A ordem "escrita, oral, material" reflete nada mais do que a ordem na qual elas foram, historicamente, percebidas como relevantes. A sequência poderia ser reversa ou embaralhada. No entanto, a percepção da importância das três é relevante e nem sempre ocorre. Por exemplo, ela parece ser negligenciada na coletânea de ensaios de Kurt Rudolph (1992). Enquanto cada uma das três principais classes de fontes tenha atraído seu próprio debate metodológico no passado (hermenêutica, problemas de acesso e assim por diante), é importante atualmente correlacioná-las de forma integrada. Uma correlação bemsucedida neste nível irá ajudar a estabilizar a disciplina do Ciência da Religião.

Cada um desses três principais tipos de fonte possui uma característica central que sobrepóe-se a dos outros. Separadamente, as características centrais de cada fonte são as seguintes:

a) Fontes escritas são linguísticas, principalmente históricas, e com uma menor abrangência do campo.

b) Fontes orais são linguísticas, especialmente do campo, e com uma menor abrangência histórica.

c) Fontes materiais são, acima de tudo, do campo e históricas, e apenas em um sentido derivado ou contextual linguísticas. Dessa forma, será visto que cada um dos três tipos de fonte compartilha uma característica central com uma das outras duas. Fontes escritas e orais sáo predominantemente linguísticas quando comparadas com fontes materiais. As fontes orais e materiais são predominantemente baseadas no campo quando comparadas com fontes escritas. Fontes materiais e escritas são predominantemente históricas quando comparadas com as fontes orais. A integração natural dessas perspectivas a serviço do Ciência da Religião pode ser ilustrada em um gráfico facilmente concebido. 


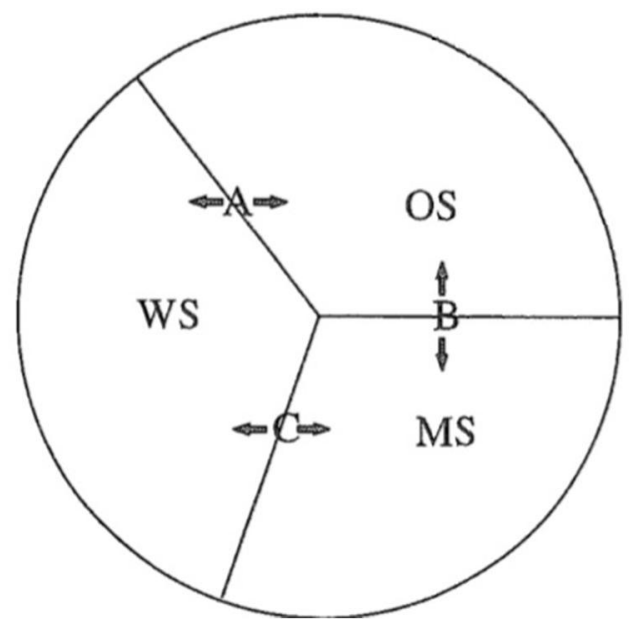

OS (oral source): Fonte oral

WS (written source): Fonte escrita

MS (material source): Fonte material

A: Conhecimento linguístico necessário

B: Trabalho de campo necessário

C: Participantes/crentes frequentemente não disponíveis

Algumas dessas relaçôes parecerão imediatamente óbvias, outras nem tanto. Fontes orais são fundamentalmente do campo e atraem os tipos de perguntas amplamente desenvolvidos na Antropologia Social e na Sociologia. Elas são "históricas" apenas nos casos em que foram reunidas e elucidadas no passado. De modo mais fraco, as fontes orais também são parte da história recente. Fontes materiais (construçôes, objetos de rituais, posiçôes corporais e movimentos etc.) podem ser novas, mas são comumente parte de uma história em andamento ou até mesmo muito antiga. Além disso, fontes materiais não têm o caráter linguístico (esse aspecto pode ser acentuado quando são negativamente referidas como "fontes não verbais"). Embora assumam seu próprio significado de contextos com um aspecto linguístico, é importante aproximar-se dos métodos apropriados de Arqueologia, Numismática, História da Arte e assim por diante. É desejável desenvolver esse subcampo da metodologia para dar conta de objetos usados principalmente, ou apenas, em contextos religiosos. Aparentemente não parece haver um nome compreensivo para isso. Termos tradicionais, como "iconografia", referem-se a isso apenas em partes. No que diz respeito às fontes escritas, é preciso ter cautela para perceber seu espectro total. Fontes escritas incluem textos bem conhecidos e textos nem táo conhecidos, mas formalmente impressionantes; inscriçóes de muitos tipos e de muitos períodos, e textos efêmeros. Tais textos podem ser integral, parcial ou apenas indiretamente religiosos em sua intenção, algo que também se aplica a artefatos. 
O ponto mais importante, que emerge de uma compreensão integral da metodologia, vem a seguir. É evidente que o método "histórico" ou "histórico-filológico" não é suficiente por si só para alcançar os requisitos metodológicos para o Ciência da Religião. Deveria ser compreendido, no entanto, que esse "extra" não surge apenas por conta da tradição de associar estudos "comparativos" com a história das religióes. Os requisitos "sistemáticos" para a Religionswissenschaft são mais abrangentes e estrênuos do que isso. Tal visão não faz justiça aos que vêm dos principais grupos de fontes. Em particular, ela falha em integrar os métodos vindos da História por um lado com os vindos da Antropologia social por outro, mesmo que ambos sejam largamente reconhecidos como de grande relevância para o Ciência da Religiáo. Quando os métodos são agrupados de maneira apropriada e integrados, o estudo da religião é bem mais forte.

\section{A formaçáo da metodologia e da teoria}

Essa parte da argumentação será feita de maneira breve, porque é um assunto bem diferente e não há a intenção aqui de passar para a teoria como tal. $\mathrm{O}$ desenvolvimento detalhado de tipologias, por exemplo, pertence ao domínio da reflexão teórica em vez da metodologia. Foi dito anteriormente que é necessário distinguir "teoria" e "método", pela simples razão de que o interesse em novas teorias é frequentemente confundido com avanço metodológico. No entanto, há dois aspectos no método que contribuem em particular para o desenvolvimento de categorias teóricas e modelos para o Ciência da Religião. Eles são, antes de tudo, a comparação e a contextualização. Onde esses métodos, ou aspectos do método, se encaixam em uma disciplina integrada para o Ciência da Religiáo?

De certa maneira, a comparação e a contextualização sobrepóem-se uma à outra. Uma comparação pode ser desenvolvida com base em dois ou mais casos da religião que estão reconhecidamente sendo estudados. Em outras palavras, várias religióes ou aspectos de religióes que tenham sido efetivamente caracterizados podem, dessa forma, ser comparados. Isso levará à construçáo de categorias temáticas elucidativas (tais como peregrinaçóes, tradição e misticismo) ou explicativas (como o sincretismo), que são internas a sistemas religiosos. No entanto, a comparação pode ser de grande interesse para a elaboração de hipóteses explanatórias, que relacionam dados de religióes com outros fatores sociológicos ou psicológicos. Isso foi massivamente exemplificado por Max Weber, por exemplo, cujo trabalho era contextual, mas também comparativo. Resumidamente, a comparação é necessária nas fases de 
reconhecimento e explanatória para o estudo da religiáo. A contextualização significa considerar um ou mais aspectos de um caso da religiáo no seu contexto histórico, sociocultural ou até mesmo biológico. Enquanto ela pode ter um caráter instrutivo na fase de reconhecimento, torna-se indispensável na fase explanatória. A contextualização é ambígua na fase de reconhecimento do estudo. Pode ser necessária para a elucidaçáo do que os crentes querem dizer. Se mal interpretada, no entanto, pode, de forma imperceptível, mas impiedosa, levar o pesquisador para longe da autocompreensão dos crentes e participantes. Teorias explanatórias, por outro lado, apenas fazem sentido dentro de um contexto.

\section{Conclusão}

O propósito desta argumentação foi ilustrar de forma breve que a integração metodológica no Ciência da Religiáo pode ser alcançada com relativa simplicidade. Claro que há uma necessidade contínua de esclarecer e discutir o assunto em pontos específicos. Estrategicamente, no entanto, o que precisamos no tempo presente nem é tanto da discussão do detalhe, mas de um foco claro nessas características do método acadêmico ou "científico" que são necessárias e frutíferas na disciplina do Ciência da Religião. Isso facilitará discussōes metodológicas e teóricas válidas, com especialistas de outros campos que necessitam, eles mesmos, de orientaçóes metodológicas distintas. Se o detalhe for deixado de lado, alguns questionamentos emergem. Foi visto que há uma necessidade de coordenação e agrupamento de vários métodos correspondentes às fontes que estão disponíveis para escrutínio. A percepção não dogmática dessas fontes leva em particular a uma correlação de métodos de trabalho de campo com métodos históricos, e termina por relativizar o último consideravelmente.

Tem sido visto, também, que o caráter especial da disciplina não repousa meramente em uma fertilizaçáo cruzada entre métodos históricos e comparativos. Essa popular correlação é equivocada e não faz justiça nem ao agrupamento de métodos apropriados relacionados às fontes, nem às maneiras com as quais a comparação se relaciona com ambas: a pesquisa de reconhecimento e a explanatória.

Finalmente, é importante insistir que, no nível de grande generalização, os procedimentos para o Ciência da Religião, embora abertos a refinamentos, não são arbitrários ou opcionais. A elucidação e a caracterização não são opcionais. No estudo acadêmico das religiôes, elas deveriam preceder a explicação. Além disso, a elucidação e a caracterização devem também ser "reconhecedoras", como acima 
explicado. Nem o ingresso religioso, como por exemplo na forma de um debate teológico, nem um reducionismo explanatório prematuro são aceitáveis nessa pesquisa. Novamente, a ampla classificação de fontes não é opcional. As fontes disponíveis não podem ser utilizadas por capricho pessoal ou por políticas da universidade. Realmente há fontes orais e materiais no campo, assim como as fontes escritas mais, ou menos, conhecidas.

Almejamos aqui a integração metodológica. A disciplina do Ciência da Religião náo pode ser dividida ao meio, por exemplo entre histórica e etnológica, só porque algumas pessoas preferem trabalhar com uma certa fonte material ou preferem ter um certo tipo de distintivo profissional. É um álibi desnecessariamente fácil dizer que o Ciência da Religião é "interdisciplinar", mesmo que seja útil de maneira preliminar". Muito frequentemente a ênfase na "interdisciplinaridade" parece sugerir abertura a uma variedade de métodos enquanto, na verdade, evita o desafio de uma reflexão metodológica. Em contraste, como foi visto acima, a disciplina do Ciência da Religião necessita, e pode, encontrar sua integração metodológica específica.

\section{Referências}

HONKO, Lauri (ed.). Science of Religion: Studies in Methodology. Proceedings of the Study Conference of the International Association for the History of Religions, held in Turku, Finland, August 27-31, 1973. The Hague: Mouton, 1979.

KATZ, Steven T. (ed.). Mysticism and Religious Traditions. Oxford: Oxford University Press, 1983.

KRISTENSEN, W. Brede. The Meaning of Religion: Lectures in the Phenomenology of Religion. The Hague, 1960.

MICHAELS, Axel (ed.). Klassiker der Religionswissenschaft: Von Friedrich Schleiermacher bis Mirce Eliade. Munchen: Beck, 1997.

PYE, Michael. Comparative Religion: An Introduction through Source Materials. Newton Abbot, 1972.

The study of religion as an autonomous discipline. Religion 12: 67-76, 1982

Religious studies in Europe: structures and desiderata. In: Klaus K. Klostermaier and Larry W. Hurtado (eds.), Religious Studies: Issues, Prospects, and

\footnotetext{
${ }^{9}$ Cf. a crítica de Don Wiebe ao avanço da "polimetodologia” durante a conferência de 1997 em Turku.
} 
$178 \quad$ Michael Pye

Proposals; pp. 39-55. Atlanta: Scholars Press. (University of Manitoba Studies in Religion, 2), 1991.

Religion: Shape and Shadow. Numen 41: 51-75, 1994.

RUDOLPH, Kurt. Geschichte und Probleme der Religionswissenschaft. Leiden: Brill, 1992.

SMART, Ninian. Dimensions of the Sacred: An Anatomy of the World's Beliefs. London: HarperCollins, 1996.

WAARDENBURG, Jacques. Religionen und Religion: Systematische Einführung in die Religionswissenschaft. Berlin: de Gruyter (Sammlung Göschen, 2228), 1986.

Recebido: 28/07/2016

Aprovado: 04/08/2016 